and, as might have been expected, he has fulfilled his task in the most complete manner. He has, to use his own words, "kept pace with the march of science." Several important additions have been made in the department of Mechanical Philosophy, and the "Elements," without detracting from their scientific value, have been to some extent judiciously popularized. Abstruse terms and investigations have been simplified, and typographical errors corrected. The edition is highly creditable to the editor.

The Fourth Edition of Dr. WILLIAM GaIRdner's work on Gout, its Causes and Cure (Churchill), embodies observations which the longer and larger experience of the author has suggested. This edition also derives increased value from the in corporation with it. of the notes of his able and experienced German translator, Dr. Braun, of Wiesbaden.

'The Sixth Edition of Sir CHARLES BELL's celebrated work on The Hand, its Mechanism and Vital Endowments as evincing Design (Murray).-This edition, revised, has been entrusted to Mr. AleXANDER SHAw. It has been rendered more interesting and complete by the addition of a general account of the author's discoveries on the nervous system.

The Eleventh Edition of Vestiges of the Natural History of Creation (Churchill).-A new issue of a most remarkable and popular work, profusely illustrated.

The Principles of Physiology applied to the Preservation of Health and to the Improvement of Physical and Mental Education. By ANDREw COMBE, M.D., Fellow of the Royal College of Physicians, Edinburgh, \&c. The Fifteenth Edision, Fdited and adapted to the present state of Physiological and Chemical Science by James Coxe, M.D., Fellow of the Royal College of Physicians of Edinburgh. pp. 336. Edinburgh, 1860.

ThIs, perhaps, was one of the most popular of Dr. Comhe's treatises. Of copies of it printed in Edinburgh, 38,000 have now been sold, whilst it is probable that in America the circulation has not fallen short of 100,000 copies. The last of the author's own edition of it, which received improvements from himself, was published as far back as 1844, three years prior to his decease. At his request, Dr. Coxe had been preparing for a new issue, which he edited and published in 1852. We are told that of this 5000 copies were printed off, and that they have been for some time exhausted. Although a good deal of new matter has been added to the present edition, the work has been kept within a readable and manageable size by the rejection of certain superfluities, \&c. The amount of varied, interesting, and useful information in this very modest volume is remarkable, and fully justifies the popularity the work has attained. It constitutes the best book to be placed in the hands of the general and youthful student of either sex, desirous of gaining some knowledge of the wondrous structure and functions of the human body, that we are acquainted with; further, the practical medical man may peruse its pages with interest and profit. A work that will honestly bear this double compliment must be of more than ordinary merit, unobtrusive as may be its pretensions.

Popular Manual of Botany; being a Development of the Rudiments of Botanical science without Technical Terms. 'By Christopher Dresser, Ph. D. With Illustrations by $\mathrm{F}$. Cathbert. Edinburgh: A. and C. Black.

STUDENTs of botany are naturally terrified by the terminology of the science, and no doubt many are deterred by this apparently insurmountable obstacle to their pursuit of knowledge. Dr. Dresser has attempted, with considerable success, to remedy this serious evil. It was scarcely to be expected, however, in so difficult a task, that there should not be some shortcomings. Still the effort is in the right direction, and many a student will, no doubt, be attracted by the simple, if "not complete, mode in which the elements of botany are presented to him in this little work.
The Sea and its Living Wonders. Translated from the Fourth Edition, and partly rewritten by the author, Dr. G. HARTwiG. With numerous Woodeuts, and 12 Chromoxylographic Plates by Henry Noel Humphreys. London: Longman.

No department of natural history is more marvellous or excites more interest than that which relates to the "great deep," and yet, previous to the appearance of Dr. Hartwig's work, it cannot be said that we possessed a complete treatise on the subject. The first part of the book describes the physical geology of the sea, and contains a lucid and full account of its magnitude, its bases, its currents, and aërial and terrestrial migrations. The second part treats of the inhabitants of the sea in all their varied and often astonishing forms. It includes also chapters on the Microscopic.Life of the Ocean, on Marine Plants and their Geographical Distribution, on the Phosphorescence of the Sea, and on the Primitive Ocean. The third part discusses the progress of maritime discovery. All these various departments exhibit the profound knowledge and unwearied industry of the author. Where all is so interesting, it is difficult to select passages for quotation. We must therefore refer the reader to the book, feeling sutisfied that he will not be disappointed by any shortcomings upon the part of the author.

The work is profusely illustrited by woodcuts, and the chro. moxylographic plates are splendid specimens of the art.

\section{A CASE OF OVARIAN DROPSY CURED BY TAPPING AND PRESSURE.}

To the Editor of THE LAANCET.

Sir,-Having observed that Mr. Baker Brown had been relating three cases of ovarian dropsy that he had brought to a successful issue by tapping succeeded by pressure, at the Medical Society of London two or three weeks since, in jus. tice to that gentleman, I think it my duty to publish, through the medium of your journal, an interesting case I treated according to his suggestions some years since.

C. $W-$, aged twenty-four, single, a milliner, of a strumous diathesis, came to me about eight years since, with an ovarian tumour of a moderate size. She was in a tolerably good state of health. I tapped her, and carefully emptied the cyst, which was unilocular. I then applied a firm and well adjusted pad, secured by a flannel bandage, as tightly as she could conveniently bear it. I also kept her on a light, dry diet, and gave her alteratives and diuretics for a week. She got up quite well, and continued so for four years, when she left the neighbourhood, and I lost sight of her. I am, Sir, yours faithfully,

EnanUeI MaY, M.R.C.S.

Fletcher House, Lower Tottenham, Dec. 1860.

\section{SUCCESSFUL RESULTS OF THE MARSHALL FALL METHOD IN SUSPENDED ANIMATION. \\ To the Eiditor of The Lancet.}

SrR, - Should you deem the following warthy of a.place in your journal, you can insert it :-

On Saturday evening last I was sudienly summoned to a man who had fallen down, and was discovered, apparently dead, stretched on the pavement. On my arrival, I found the surface of the body cold ; no pulse at the wrist. I instantly unfastened his necktie, and placing my hand over his heart could perceive no pulsation; I applied my ear with no better results. I then commenced the prone and postural movements, and was soon repaid by a slight inspiration, shortly followed by others more powerful. I then had him conveyed to an adjoining house, where in a short time he was sufficiently recovered to permit of his removal. He is now well, and pursuing his usual occupation.

It is with great pleasure I record the above, since it will add another successful case to that long column, which will ever remain a lasting memorial to the memory of our departed friend.

I remain, Sir, your obedient servant,

J. R. LANsDowr, L.R.C.P. Ed., M.R.C.S.

Bank-street, Sheffield, Noremier 27 th, 1860 . 